\title{
INTERNATIONALIZATION PERSPECTIVE OF PANGASINAN STATE UNIVERSITY: OPEN UNIVERSITY SYSTEMS
}

\author{
Dr. Phillip QUERODA \\ ORCID: 0000-0002-3576-7143 \\ Faculty of Education \\ Pangasinan State University \\ Pangasinan, PHILIPPINES
}

Received: 19/08/2018 Accepted: 13/04/2020

\begin{abstract}
This study was administered to determine the perspective of Pangasinan State University - Open University Systems (PSU-OUS) towards internationalization as perceived by the academic unit's professors as the initial step for its implementation and realization.

The method of research that was used in the study is descriptive. Total population sampling technique was used in determining the respondents, all of whom 20 faculty members of PSU-OUS. Mean average and 4-point Likert scale were used in analyzing and interpreting the data gathered. The questionnaire was validated by experts which include deans and directors in the graduate school level to ensure its validity and reliability. Google Forms were used as data gathering tool.

The level of readiness of PSU-OUS in internationalization as perceived by faculty members is moderately ready. The faculty members' level of understanding towards internationalization is also moderate in extent. Further, faculty members perceived a high extent of opportunity in relation to internationalization. Finally, faculty members discern the internationalization challenges as less serious in PSU-OUS.

PSU-OUS and other institutions across the world should give emphasis on indicators in the understanding of internationalization such as international students' recruitment, facilities and support system and diversity of income generation. Institutions should intensify its awareness on internationalization through seminars and forums. Further, the institutions should review its policies regarding the perceived very serious challenges of internationalization such as high cost of investing in building and infrastructure, lack of efficient quality assurance mechanism, and lack of stakeholders' and staff orientation.
\end{abstract}

Keywords: Internationalization Perspective, Open University Internationalization, Internationalization Readiness

\section{INTRODUCTION}

Internationalization has been one of the trends in the education industry in the past few years brought about by the educational paradigm shift due to globalization especially in higher education. While innovation correlates opportunities, some may be reluctant to the changes it might bring which may affect their way of life.

A task force of NAFSA members appointed in 2008 created a definition of internationalization for NAFSA to use to guide its work. After reviewing the resources that have previously addressed the concept of internationalization, the task force proposed a working definition for NAFSA's purposes: "Internationalization is the conscious effort to integrate and infuse international, intercultural, and global dimensions into the ethos and outcomes of postsecondary education. To be fully successful, it must involve active and responsible engagement of the academic community in global networks and partnerships" (Nafsa.org, 2011). The definition depicts the vagueness of internationalization program, and certainly, its impact is somehow comprehensive to a certain institution including the community where it belongs or the country where it is located. 
Internationalization of higher education is the top stage of international relations among universities. It is no longer regarded as a goal in itself, but as a means to improve the quality of education. The knowledge translation and acquisition, mobilization of talent in support of global research and enchantment of the curriculum with international content are considered to be the benefits of internationalization of higher education. Though internationalization holds many positives to higher education, there are grave risks associated with this multifaceted and growing phenomenon including commercial profit, academic colonization, and difficulty in ensuring quality education. The current review has implications for educational policymakers to provide positive benefits to the higher education institutions and the countries concerned (Jibeen \& Khan, 2015).

Hayle (2008) listed four benefits of internationalization to either students and/or university in itself as follows: (1) a broadened knowledge and understanding of other nations, cultures, and global issues; (2) networking and the development of social and emotional skills; (3) the generation of revenue; and (4) contributing to the reproduction of Western knowledge. Overall, these themes collectively speak to the institution's internationalization goals, and a measure of commitment to more than one internationalization goal, with less than a half of the student participants reporting that developing global competence was the main benefit derived.

Overall, the Philippines compare favorably with ASEAN peer countries. However, an area of weakness is the relative lack of the openness to international students and academics. The process for student visa applications is complex and similarly, international academics face significant difficulties should they wish to practice their profession in the Philippines (Killingley \& Llieva, 2018).

Philippines has a comprehensive transnational education (TNE) strategy, which sets out the terms of engagement between domestic and international higher education institutions (HEIs). From an overseas HEI perspective, however, the limitations on operating through a local partner institution, which must have at least 60 percent ownership of the venture, represent a significant setback. HEIs with strong global brands, many of which will be keen to retain ownership and direct control over the quality of the education being provided. Philippines' ability to retain and attract talent is less strong than its peers (Killingley and Llieva, 2018).

The prospects of internationalizing higher education in the Philippines were contextualized within the present education system that is experiencing problems related to efficiency, quality, equity in access, and other external factors. Given this context, it was suggested that participation in international education programs might be limited to students from high-income families, and to institutions with strong financial resources that can be channeled to development programs that will enable them to meet the requirements of these international activities. There is a strong likelihood that international programs might lead to the intensification of the existing weaknesses in Philippine higher education (Bernardo, 2002).

In Pangasinan State University (PSU), the initiative for internationalization is embedded in its strategic goals particularly on SG no. 5, "Responsive to Globalization and Diversity"(Psu.edu.ph, 2018). If globalization is the end goal, then internationalization is a task that has to be completed in order for the end goal to be achieved (Norvet, 2016). Since PSU - Open University Systems (OUS) is the academic unit of PSU that offers online distance learning which is closely connected to internationalization, it's a promising avenue for its commencement. Distance learning is now an integral part of mass higher education systems in emerging countries and could be an essential tool for internationalizing their systems. It is estimated that at least 21 million students from emerging countries have studied through distance higher education in recent years and this number is growing very quickly (Ergin \& Morche, 2018).

Consequently, it is the opportune time to determine internationalization perspective of Pangasinan State University - Open University Systems in terms of readiness, understanding, opportunities, and challenges as perceived by the faculty members before its implementation to uncover valuable facts that may be employed as bases for strategic planning.

\section{Statement of the Problem}

This study is determined internationalization perspective of Pangasinan State University - Open University Systems. Specifically, the study was conducted to answer the following questions: (a) What is the level of readiness of PSU-OUS in internationalization as perceived by faculty members? (b) What is the level of understanding of PSU-OUS faculty members in Internationalization? (c) What is the extent of opportunities of PSU-OUS in Internationalization as perceived by faculty members? and (d) What is the extent of the seriousness of the potential Internationalization challenges of PSU-OUS as perceived by faculty members? 


\section{RESEARCH METHODOLOGY}

The descriptive method of research was used in the study. The descriptive research describes the existing conditions to be investigated. Descriptive research design is a valid method for researching specific subjects and as a precursor to more quantitative studies. While there are some valid concerns about the statistical validity, as long as the limitations are understood by the researcher, this type of study is an invaluable scientific tool (Shuttleworth, 2008).

There are 20 formidable faculty members of PSU-OUS accros all academic programs served as respondents in the study. The academic programs where these professors teach includes Doctor of Education (Ed.D.) major in Educational Management, Master of Arts in Education (MAEd.) major in Educational Management and Instructional Leadership, Master in Development Management major in Public Management and Master of Science in Fisheries. In determining the respondents, total population sampling technique was used. Total population sampling is a type of purposive sampling technique where you choose to examine the entire population (i.e., the total population) that have a particular set of characteristics ("Total population sampling," 2012). The respondents are the faculty members of PSU-OUS across all programs, namely: Doctor of Education major in Educational Management, Master of Arts in Education major in Educational Management and Instructional Leadership, Master of Science in Fisheries and Master in Development Management.

Quantitative data collection method is used in the study particularly web-based questionnaire thru google forms. The questionnaire is divided in four parts. The first part focused on level of readiness of PSU-OUS in internationalization, the second part in on the level of understanding to internationalization, the third part is on extent of opportunities in internationalization, and the last part dealt with level of seriousness of challenges in internationalization. Quantitative data collection methods are based on random sampling and structured data collection instruments. Findings of quantitative studies are usually easy to present, summarize, compare and generalize (Research Methodology, 2018). The indicators from the questionnaire were adapted from the manuscript of Dr. Elmer B. De Leon. Social media such as Facebook and E-mail were utilized in gathering the data.

\section{RESULTS AND DISCUSSION}

\section{What Is The Level Of Readiness Of Psu-Ous In Internationalization As Perceived By Faculty Members?}

Table 1. shows the level of readiness of faculty members of PSU-OUS in internationalization.

Table 1. Level of Readiness of PSU-OUS in Internationalization as Perceived by Faculty Members

\begin{tabular}{|c|c|c|}
\hline Indicators & Mean & Description \\
\hline 1. Mobility and Exchanges for Students and Teachers & 3.65 & Very Much Ready \\
\hline 2. International and Intercultural Understanding/Networking & 3.60 & Very Much Ready \\
\hline 3. Curriculum and Instruction & 3.60 & Very Much Ready \\
\hline 4. Research Collaboration & 3.45 & Moderately Ready \\
\hline 5. Academic Standards and Quality & 3.15 & Moderately Ready \\
\hline 6. Cooperation and Development Assistance & 2.85 & Moderately ready \\
\hline 7. International Students Recruitment & 2.50 & Slightly Ready \\
\hline 8. Facilities and Support System & 2.20 & Slightly Ready \\
\hline 9. Diversity of Income Generation & 2.00 & Slightly Ready \\
\hline Total & 3.00 & Moderately Ready \\
\hline
\end{tabular}

Indicators were adapted from Dr. Elmer B. De Leon

Overall, the level of readiness of PSU-OUS in internationalization as perceived by faculty members is moderate with an overall mean value of 3.00. Quite a similar result from the study of Agosto and Sanchez (2017) revealed as to K-12 curriculum, all the respondent schools were very much ready for internationalization while on teachers' qualification and student services, the schools were moderately ready but, less ready for physical plant and facilities. 


\section{What is the Level of Understanding of PSU-OUS Faculty Members in Internationalization?}

Table 2 depicts the level of understanding of the faculty members of PSU-OUS in internationalization.

Overall, the level of understanding of PSU-OUS in internationalization as perceived by faculty members is moderate with an overall mean value of 3.30 .

In particular, the faculty members have high extent of understanding on the following indicators as follows: Internalization promotes activities such as curriculum, student/faculty exchange, technical assistance, and international students; it refers to a series of international activities like academic mobility for students and learners, international linkages, partnerships, projects, academic programs and research initiatives; it focuses on issues on student admission procedures, form of instruction, teaching staff, curriculum development and quality assurance; internationalization activities should be carefully planned, well-resourced and have the involvement and support of all key stakeholders; and the development of curricula and programs is a means towards developing appropriate competencies of students to be successful national and international citizens with mean values of $4.00,3.90,3.80,3.80$, and 3.60 respectively.

In addition, the faculty members have moderate extent of understanding on the following indicators, namely: internationalization emphasizes the development of skills, knowledge, attitudes, and values in students, faculty and staff; it leads to inclusion of an international dimension in order to enhance quality of teaching and learning and to achieve the desired competencies; it stresses integration or infusion of international/intercultural dimension into teaching, research and service through a wide range of activities, policies and procedures; It emphasizes creating a culture or climate that values and supports international/intercultural perspectives and initiatives; it will ensure the nation's economic competitiveness; it is about relating to the diversity of cultures that exist within countries, communities, and institutions; reasons for internationalization include interest in international security, maintenance of economic competitiveness, and fostering of human understanding across nations; it encompasses the policies and practices undertaken by academic systems and institutions to improve the quality of education; and it is closely linked with financial reduction, the rise of academic entrepreneurialism and genuine philosophical commitment to cross-cultural perspectives in the advancement and dissemination of knowledge with mean values of 3.50, 3.40, 3.35, 3.30, 3.25, 2.90, 2.85, 2.85 and 2.55 respectively. 
Table 2. Level of Understanding of PSU-OUS Faculty Members in Internationalization

\begin{tabular}{|c|c|c|}
\hline Indicators & Mean & Description \\
\hline $\begin{array}{l}\text { 1. Internalization promotes activities such as curriculum, student/faculty } \\
\text { exchange, technical assistance, and international students. }\end{array}$ & 4.00 & High Extent of Understanding \\
\hline $\begin{array}{l}\text { 2. It refers to a series of international activities like academic mobility } \\
\text { for students and learners, international linkages, partnerships, projects, } \\
\text { academic programs and research initiatives. }\end{array}$ & 3.90 & High Extent of Understanding \\
\hline $\begin{array}{l}\text { 3. It focuses on issues of student admission procedures, form of } \\
\text { instruction, teaching staff, curriculum development and quality } \\
\text { assurance. }\end{array}$ & 3.80 & High Extent of Understanding \\
\hline $\begin{array}{l}\text { 4. Internationalization activities should be carefully planned, } \\
\text { well-resourced and have the involvement and support of all key } \\
\text { stakeholders. }\end{array}$ & 3.80 & High Extent of Understanding \\
\hline $\begin{array}{l}\text { 5. The development of curricula and programs is a means towards } \\
\text { developing appropriate competencies of students to be successful } \\
\text { national and international citizens. }\end{array}$ & 3.60 & High Extent of Understanding \\
\hline $\begin{array}{l}\text { 6. It emphasizes the development of skills, knowledge, attitudes and } \\
\text { values in students, faculty and staff. }\end{array}$ & 3.50 & Moderate Extent of Understanding \\
\hline $\begin{array}{l}\text { 7. It leads to the inclusion of an international dimension in order to } \\
\text { enhance the quality of teaching and learning and to achieve the desired } \\
\text { competencies. }\end{array}$ & 3.40 & Moderate Extent of Understanding \\
\hline $\begin{array}{l}\text { 8. It stresses integration or infusion of international/intercultural } \\
\text { dimension into teaching, research, and service through a wide range of } \\
\text { activities, policies and procedures. }\end{array}$ & 3.35 & Moderate Extent of Understanding \\
\hline $\begin{array}{l}\text { 9. It emphasizes creating a culture or climate that values and supports } \\
\text { international/intercultural perspectives and initiatives. }\end{array}$ & 3.30 & Moderate Extent of Understanding \\
\hline 10. It will ensure the nation's economic competitiveness. & 3.25 & Moderate Extent of Understanding \\
\hline $\begin{array}{l}\text { 11. It is about relating to the diversity of cultures that exist within } \\
\text { countries, communities and institutions. }\end{array}$ & 2.90 & Moderate Extent of Understanding \\
\hline $\begin{array}{l}\text { 12. Reasons for internationalization include interest in international } \\
\text { security, maintenance of economic competitiveness, and the fostering } \\
\text { of human understanding across nations. }\end{array}$ & 2.85 & Moderate Extent of Understanding \\
\hline $\begin{array}{l}\text { 13. It encompasses the policies and practices undertaken by academic } \\
\text { systems and institutions to improve the quality of education. }\end{array}$ & 2.85 & Moderate Extent of Understanding \\
\hline $\begin{array}{l}\text { 14. It is closely linked with financial reduction, the rise of academic } \\
\text { entrepreneurialism and genuine philosophical commitment to } \\
\text { cross-cultural perspectives in the advancement and dissemination of } \\
\text { knowledge. }\end{array}$ & 2.55 & Moderate Extent of Understanding \\
\hline \multirow{2}{*}{$\begin{array}{l}\text { 15. It is crucial that governments and individual institutions formulate } \\
\text { goals and strategies that should be quantified in order to measure } \\
\text { performance. }\end{array}$} & 2.50 & Little Extent of Understanding \\
\hline & 3.30 & $\begin{array}{l}\text { Moderate Extent of } \\
\text { Understanding }\end{array}$ \\
\hline
\end{tabular}

Indicators were adapted from Dr. Elmer B. De Leon

On the other hand, the faculty members have a little extent of understanding in an indicator, it is crucial that governments and individual institutions formulate goals and strategies that should be quantified in order to measure performance with a mean value of 2.50 .

In a study made or conducted by Wilhborg (2010), he found out that teachers were found to experience and understood internationalization in different ways, which could be related to two perspectives within their working context; an organizational didactic or an educational didactic. The findings imply the importance of reinforcing an understanding of internationalization in connection with a didactical theoretical awareness. 


\section{What is the Extent of Opportunities of PSU-OUS in Internationalization as Perceived by Faculty?}

Table 3 displays the extent of opportunities of PSU-OUS in internationalization as perceived by faculty members.

Overall, the extent of opportunities of PSU-OUS in internationalization as perceived by faculty members is high with a mean of 3.72 .

In particular, the faculty members perceived high extent of opportunities as far as internationalization is concern on the following indicators, to wit: internationalizing curricula through international studies; globally competitive faculty and students; student and staff mobility; transnational distance education; global competitiveness and critical thinking; global job opportunities and experience for students; research collaborations; educational innovation opportunities; intercultural integration and mutual agreement; international networks; international quality assurance; and faculty and student international scholarship opportunities with mean values of $4.00,4.00,3.90,3.90,3.90,3.85,3.80,3.80,3.70,3.60,3.60$, and 3.55 respectively.

Table 3. Extent of Opportunities of PSU-OUS in Internationalization as Perceived by Faculty Members

\begin{tabular}{lcc}
\hline Indicators & Mean & Description \\
\hline 1. Internationalizing curricula through international studies & 4.00 & High Extent of Opportunity \\
2. Globally competitive faculty and students & 4.00 & High Extent of Opportunity \\
3. Student and staff mobility & 3.90 & High Extent of Opportunity \\
4. Transnational distance education & 3.90 & High Extent of Opportunity \\
5. Global competitiveness and critical thinking & 3.90 & High Extent of Opportunity \\
6. Global job opportunities and experience for students & 3.85 & High Extent of Opportunity \\
7. Research collaborations & 3.80 & High Extent of Opportunity \\
8. Educational innovation opportunities & 3.80 & High Extent of Opportunity \\
9. Intercultural integration and mutual agreement & 3.70 & High Extent of Opportunity \\
10. International networks & 3.60 & High Extent of Opportunity \\
11. International quality assurance & 3.60 & High Extent of Opportunity \\
12. Faculty and student international scholarship opportunities & 3.55 & High Extent of Opportunity \\
13. Twinning and articulation programs & 3.40 & Moderate Extent of Oppor \\
14. National and international distinction & 3.40 & Moderate Extent of Oppor \\
15. Strong student learning outcomes & 3.35 & Moderate Extent of Oppor \\
\hline
\end{tabular}

Indicators were adapted from Dr. Elmer B. De Leon

On the other hand, the faculty members perceived a moderate extent of opportunities in the following indicators, namely: twinning and articulation programs; national and international distinction; and strong student learning outcomes with mean values of $3.40,3.40$, and 3.35 respectively.

In a journal article written by Knight (2007), she stated that the process of internationalization affords many benefits to higher education based on the results of the 2005 International Association of Universities (IAU) Survey wherein there is overwhelming agreement (96 percent of responding institutions from 95 countries) that internationalization brings benefits to higher education. She further mentioned that the two most important benefits identified by higher education institutions are more internationally oriented staff/students and improved academic quality. The three least-important benefits according to these same institutions are national and international citizenship, revenue generation, and brain gain.

Sankat (2015) also enumerated some highlights of internationalization to universities such as fostering human development through understanding and respect across nations, expanding and sustaining avenues for economic competitiveness, promoting academic entrepreneurialism, and evidence suggests that many citizens are employed by foreign-owned firms - this is likely to be an increasing trend. 


\section{What is the Perceived Level of Seriousness of Challenges in Internationalization of PSU-OUS?}

Table 4 exposes the level of seriousness of the challenges of internationalization as perceived by the faculty members of PSU-OUS.

Overall, the faculty members perceived less serious on the challenges of internationalization with an overall mean of 2.18 .

In particular, the faculty members perceived very serious on the challenges of internationalization as follows: the high cost of investing in building and infrastructure; lack of efficient quality assurance mechanism; and lack of stakeholders' and staff orientation with mean values of 3.70, 3.60, and 3.55 respectively. On the other hand, the faculty members perceived moderately serious on the following challenges, such as: lack of available technology resources; lack of cost efficiency due to insufficient demand for internationalized program and collaboration opportunities; limited time for preparation and planning; lack of stakeholders' understanding and acceptance; and lack of management support system with mean values of 3.30, 3.20, 2.65, 2.55 and 2.55 respectively.

Table 4. Perceived Level of Seriousness of Challenges in Internationalization of PSU-OUS

\begin{tabular}{|c|c|c|}
\hline Indicators & Mean & Description \\
\hline 1. High cost of investing in building and infrastructure & 3.70 & Very Serious \\
\hline 2. Lack of efficient quality assurance mechanism & 3.60 & Very Serious \\
\hline 3. Lack of stakeholders' and staff orientation & 3.55 & Very Serious \\
\hline 4. Lack of available technology resources & 3.30 & Moderately Serious \\
\hline $\begin{array}{l}\text { 5. Lack of cost efficiency due to insufficient demand for internationalized program } \\
\text { and collaboration opportunities }\end{array}$ & 3.20 & Moderately Serious \\
\hline 6. Limited time for preparation and planning & 2.65 & Moderately Serious \\
\hline 7. Lack of stakeholders' understanding and acceptance & 2.55 & Moderately Serious \\
\hline 8. Lack of management support system & 2.55 & Moderately Serious \\
\hline 9. Student and the global community expectations & 2.20 & Less Serious \\
\hline 10. Decline of quality education due to marketization focus & 2.20 & Less Serious \\
\hline 11. Lack of pedagogic competence & 2.20 & Less Serious \\
\hline 12. International competition for students and staff & 2.05 & Less Serious \\
\hline 13. Racism and ethnocentrism & 1.40 & Not At All Serious \\
\hline 14. Lack of respect for local culture and environment & 1.40 & Not At All Serious \\
\hline 15. Students' cultural conflict and untoward attitude & 1.35 & Not At All Serious \\
\hline 16. Inability to communicate in English & 1.30 & Not At All Serious \\
\hline 17. Possible brain drain due to constant mobility & 1.30 & Not At All Serious \\
\hline 18. Students' inability to manage cultural differences & 1.10 & Not At All Serious \\
\hline 19. Influx of immigrants for permanent residency in the country & 1.00 & Not At All Serious \\
\hline 20. Lack of Faculty and staff technical skills and expertise & 1.00 & Not At All Serious \\
\hline Total & 2.18 & Less Serious \\
\hline
\end{tabular}

Indicators were adapted from Dr. Elmer B. De Leon

In addition, the faculty members perceived less serious on the challenges of internationalization in the following indicators, to wit: student and the global community expectations; decline of quality education due to marketization focus; lack of pedagogic competence; and international competition for students and staff with mean values of 3.30, 3.20, 2.65 and 2.05 respectively. In different circumstances, the faculty members perceived the following international challenges as not serious at all, such as: racism and ethnocentrism; lack of respect for local culture and environment; students' cultural conflict and untoward attitude; inability to communicate in English; possible brain drain due to constant mobility; students' inability to manage cultural differences; influx of immigrants for permanent residency in the country; lack of faculty and staff technical skills and expertise with mean values of $1.40,1.40,1.35,1.30,1.30,1.10,1.00$ and 1.00 respectively. 
In a study conducted by Braskamp (2009), he pointed out four issues for internationalization in higher education that includes the language of internationalization, appropriate and effective interventions, assessment and evaluation, and appropriate and effective interventions.

\section{CONCLUSION}

From the preceding findings, the following conclusions are drawn.

PSU-OUS is modestly ready for internationalization particularly on research collaboration, academic standards and quality and cooperation and development assistance.

The institution has a reasonable understanding about internationalization. To name a few, the institution believes that institution emphasizes the development of skills, knowledge, attitudes and values in students, faculty and staff. Institution also believes the internationalization leads to the inclusion of an international dimension in order to enhance the quality of teaching and learning and to achieve the desired competencies. Further, internationalization stresses integration or infusion of international/intercultural dimension into teaching, research, and service through a wide range of activities, policies and procedures.

The institution has high extent of internationalization opportunities evident on internationalizing curricula through international studies, globally competitive faculty and students, student and staff mobility, transnational distance education, global competitiveness and critical thinking, to name a few.

Internationalization challenges are less serious in the institution specifically on student and the global community expectations, decline of quality education due to marketization focus, lack of pedagogic competence, and international competition for students and staff.

\section{RECOMMENDATIONS}

Based on the above-mentioned findings and conclusion, the following recommendations are hereby presented. Faculty members should enhance their readiness for internationalization particularly on international student's recruitment, facilities and support system, and diversity of income generation. They should also develop their understanding on internationalization; for instance, on issues that governments and individual institutions formulate goals and strategies that should be quantified in order to measure performance. In addition, faculty members should sustain their perceived high extent of internationalization opportunities. Further, they should sustain their optimistic view that potential problems or challenges of internationalization are less serious.

\section{BIODATA and CONTACT ADDRESSES of AUTHOR}

Dr. Phillip QUERODA is a Doctor of Education major in Educational Management. He is an Assistant Professor IV of Pangasinan State University (PSU) and

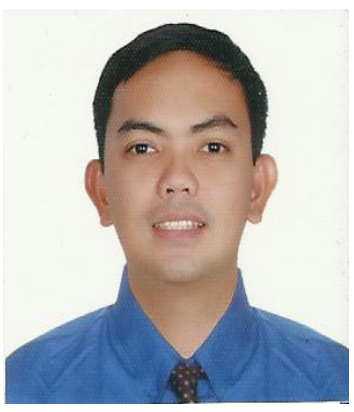
currently designated as the Director for Expanded Tertiary Education Equivalency and Accreditation Program (ETEEAP). He teaches Professional Education subjects in the Teacher Education Program. He is affiliated with the Open University Systems of PSU and Southeast Asian Minister of Education, Organization, Innovation and Technology (SEAMEO-INNOTECH). He is actively engaged in research as the Editor-in-Chief of the Multidisciplinary Research Journal of PSU and an associate member of National Research Council of the Philippines (NRCP). He has conducted researches on pedagogy, instructional strategies and online distance learning and presented his outputs in research conferences here and abroad. He has produced numerous research articles to refereed journals and Scopus-Indexed Publications.

Phillip QUERODA

Pangasinan State University College of Education, Professional Education Department

Address: Alvear Street, Poblacion, Lingayen, Pangasinan, Philippines

Phone: +639338706671

E-mail: phillipqueroda@gmail.com 


\section{REFERENCES}

Agosto, J. \& Sanchez, R. (2017). Readiness of DepEd schools for internationalization. International Journal of Current Research, 9(12) pp. 63655-63662. Retrieved from: http://www.journalcra.com/sites/ default/files/28145.pdf

Braskamp, L. (2009). Internationalization in Higher Education: Four Issues to Consider. Journal of College and Character, 10(6). https://doi.org/10.2202/1940-1639.1688

De Leon, E. (2017). Philippine TEIs internationalization practice and experience: elucidating perspectives, challenges and opportunities. PAFTE

Hayle, E. (2008). Educational benefits of internationalizing higher education: the students' perspectives: $A$ thesis in Master of Education Queen's University, Kingston, Ontario, Canada

Jibeen, T. and Khan, K. (2015). Internationalization of Higher Education: Potential Benefits and Costs. International Journal of Evaluation and Research in Education (IJERE), 4(4), p.196. Retrieved from: https://files.eric.ed.gov/fulltext/EJ1091722.pdf

Knight, J. (2005). 2005 IAU Global Survey on Internationalization of Higher Education. Retrieved from: https://www.iau-aiu.net/IMG/pdf/key_results_2005_1.pdf

Knight, J. (2007). Internationalization Brings Important Benefits as Well as Risks. Retrieved from: https:// ejournals.bc.edu/ojs/index.php/ihe/article/download/7939/7090

Nafsa.org. (2011). NAFSA's contribution to internationalization of higher education. Retrieved from: https://www.nafsa.org/_/File/_/2011_izn_contributions.pdf

Norvet, A. (2016). What's the Difference? Internationalization vs. Globalization. Retrieved from: http:// daily.unitedlanguagegroup.com/stories/editorials/internationalization-globalization

Psu.edu.ph. (2018). Strategic Goals » Pangasinan State University. Retrieved from: http://psu.edu.ph/ strategic-goals/

Research Methodology. (2018). Quantitative data collection methods. Retrieved from: https://researchmethodology.net/research-methods/quantitative-research/

Sankat, C. (2015). The benefits of internationalization. The Association of Commonwealth Universities. Retrieved from: https://www.acu.ac.uk/membership/member-communities/internationalisation/ articles/benefits-internationalisation

Shuttleworth, M. (2008). Descriptive research design. Retrieved from: https://explorable.com/descriptiveresearch-design

Total population sampling. (2012). Retrieved from: http://dissertation.laerd.com/total-populationsampling.php

Wihlborg, M. (2004). Teachers' understanding of internationalization as an essential part of nursing education in Sweden. Scandinavian. Journal of Educational Research, 48(5), pp.529-546. Retrieved from: https://www.tandfonline.com/doi/abs/10.1080/003138042000272168 